\title{
Plexiform Schwannoma: A Report of Two Unusual Cases, and a Review of the Literature
}

\author{
Shabnum Ali1,2*, Leandros Vassiliou ${ }^{1,3}$, Philip Stenhouse ${ }^{1,3}$ \\ ${ }^{1}$ Department of Oral and Maxillofacial Surgery, Queen Mary's Hospital, Sidcup, UK \\ ${ }^{2}$ Department of Special Care Dentistry, Bristol Dental Hospital, Bristol, UK \\ ${ }^{3}$ Department of Oral and Maxillofacial Surgery, King's College Hospital, London, UK \\ Email: ${ }^{*}$ Shabnum ali@hotmail.com
}

Received 22 February 2014; revised 24 March 2014; accepted 2 April 2014

Copyright (C) 2014 by authors and Scientific Research Publishing Inc.

This work is licensed under the Creative Commons Attribution International License (CC BY). http://creativecommons.org/licenses/by/4.0/

c) (i) Open Access

\begin{abstract}
Plexiform schwannoma is a benign tumour arising from the sheath of myelinated nerve fibres that may occur in any part of the body. It is very rare in the head and neck region and poses diagnostic challenges. Here we present two unusual cases. The first is about a fifteen-year-old boy with a large plexiform schwannoma in the right retro maxillary region, extending up to but not invading the orbit. Initial cytology reported it as a pleomorphic adenoma, but histological findings after excision confirmed it to be a benign plexiform schwannoma. A zygomatic osteotomy was required to excise the tumour in its entirety. The second reported case is about solitary lesion on the tongue of a 46-year-old Chinese man, clinically mimicking a mucocoele. This case report highlights the diagnostic challenges posed by plexiform schwannoma, and the role of imaging and cytopathology, as well as the importance of definitive histopathological analysis. It also describes the surgical management of these lesions, and provides a review of the literature, in particular of cases occurring in the head and neck region.
\end{abstract}

\section{Keywords}

Plexiform Schwannoma, Benign Nerve Sheath Tumour

\section{Introduction}

Schwannoma is a benign tumour arising from the sheath of myelinated nerve fibres that may occur in any part of

*Corresponding author. 
the body [1]. Plexiform schwannoma is a rare variant of schwannoma that accounts for only $5 \%$ of all schwannomas, and typically shows a plexiform or multinodular growth pattern [2]. It was first described by Harkin and Reed in 1978 [3], and very few cases had since been reported. Plexiform schwannoma usually develops in the dermis or subcutaneous tissue, and it is uncommon for the schwannoma to develop in deep seated nerves. It is a benign, sporadic neoplasm and is characterized histologically by small, round lesional cells surrounding collagenous cores forming rosette-like structures [4]. This rare benign tumour is worthy of recognition because it can be misdiagnosed as plexiform neurofibroma. Differentiation from plexiform neurofibroma is important because the latter is pathognomonic of von Recklinghausen disease and carries a significant risk of malignant transformation. Plexiform schwannoma is, in contrast, not necessarily associated with von Recklinghausen disease [neurofibromatosis type I] and malignant transformation has never been observed [5].

\section{Case Report 1}

A 15-year-old boy presented with a diffuse swelling over his right cheek causing obvious facial asymmetry. Intraorally a $5 \mathrm{~cm}$ lump was palpable in the buccal mucosa. The patient had been aware of this lesion being present for a year, with no change in size and no associated symptoms. There was no evidence of any other similar lesions or syndromes. Mouth opening was normal. The patient was medically fit and well, and a non-smoker. MRI scan revealed a $5.5 \mathrm{~cm}$ by $4 \mathrm{~cm}$ homogenous mass in the right retro maxillary region, causing an anterior bowing of the maxillary antrum without any invasion into the orbit, maxilla, mandible, oropharynx, nasal cavity, or the surrounding muscles. The lesion was encapsulated, indicating that it was slow growing. Internal septi and an area of central necrosis were visible on the contrast images. No intracranial lesions were present. The differential diagnosis at this stage included a low grade sarcoma, angiofibroma or a pleomorphic adenoma arising from a minor salivary gland (Figure 1).

A FNA was subsequently carried out suggesting the diagnosis of pleomorphic adenoma from an accessory parotid gland. The lesion was excised using an intraoral approach under general anaesthesia. A zygomatic osteotomy was required in order to access and fully excise the lesion. Histopathology report showed that the lesion was infact a plexiform schwannoma with no evidence of malignancy. One year post operatively, the patient showed no signs of recurrence, with good remodelling of the zygomatico maxillary complex, and normal mouth opening.

\section{Case Report 2}

A 46-year-old Chinese man presented with a long standing swelling on his tongue which was slowly growing and asymptomatic. The patient was fit and well, a non-smoker, with no other similar lesions or syndromes, and no evidence of any neurological problems. A $1 \mathrm{~cm}$ firm, round lump was present on the left dorsum of the tongue, with no induration. Differential diagnoses included granular cell tumour or mucocele. The lesion was excised with primary closure. Histopathology showed a $12 \mathrm{~mm}$ by $5 \mathrm{~mm}$ plexiform schwannoma with no mitotic activity and no evidence of malignancy (Figure 2).

\section{Discussion}

Schwannoma is a benign, encapsulated, slow growing, neural neoplasm of Schwann cell origin [6]. Plexiform schwannoma is a rare variant of schwannoma that accounts for only $5 \%$ of all schwannomas, with a plexiform or multinodular growth pattern which may or may not be apparent macroscopically [2] [7] [8]. It is usually found on the trunk, head, neck and upper extremities most often involving the skin and subcutaneous tissues. $25 \%$ to $40 \%$ of all schwannomas are considered to affect the head and neck region, and $1 \%$ are intraoral [9]. Gallo, et al. 1977 reported that the tongue was the most common site of occurrence in the oral cavity [10]. Clinically schwannoma presents as a solitary circumscribed nodule, rarely being multinodular [11]. Most reported cases describe small, slow growing tumours that are asymptomatic, although pain and paraesthesia may occur. Other symptoms include disturbance in mastication, phonation, dyspnoea or dysphagia, depending on the location of tumour [12]. In the tongue, the base is commonly affected [9] while the tip is the least affected part [13]. The literature shows no gender or age predilection but schwannomas are rarely reported in the younger age group. It is believed that these lesions arise from proliferation of Schwann cells at a point inside the perineurium, which causes a displacement and compression of the surrounding normal nerve tissue [14] and trauma and neurofibromatosis type 2 are well-recognized risk factors for these lesions [15]. 


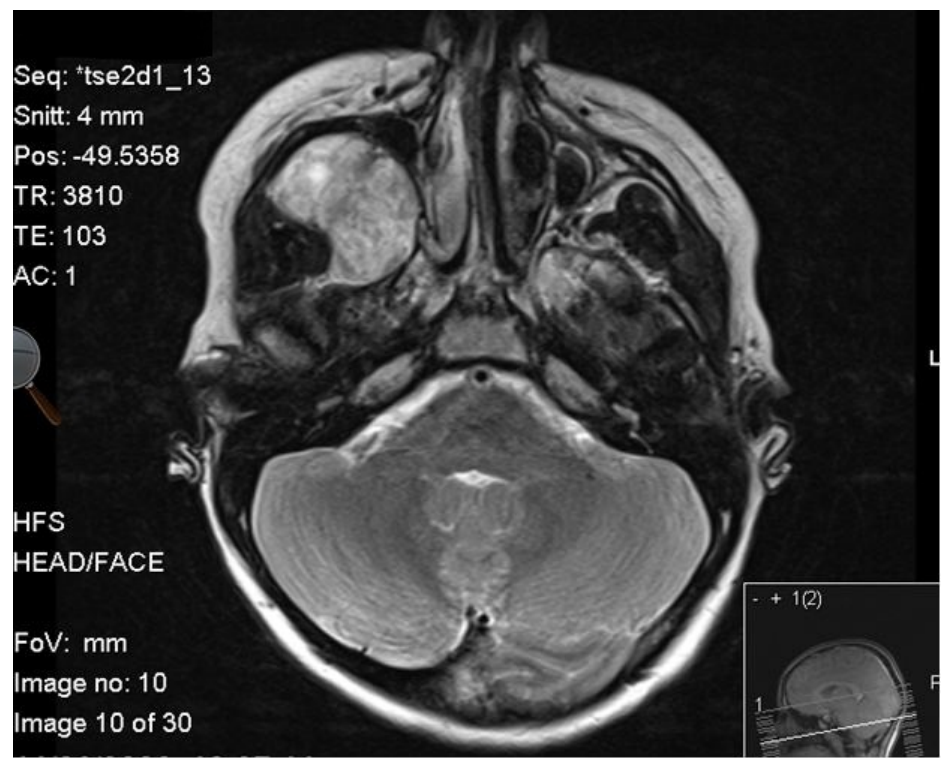

Figure 1. This image shows the lesion in the right retro maxillary region causing an anterior bowing of the maxillary antrum.

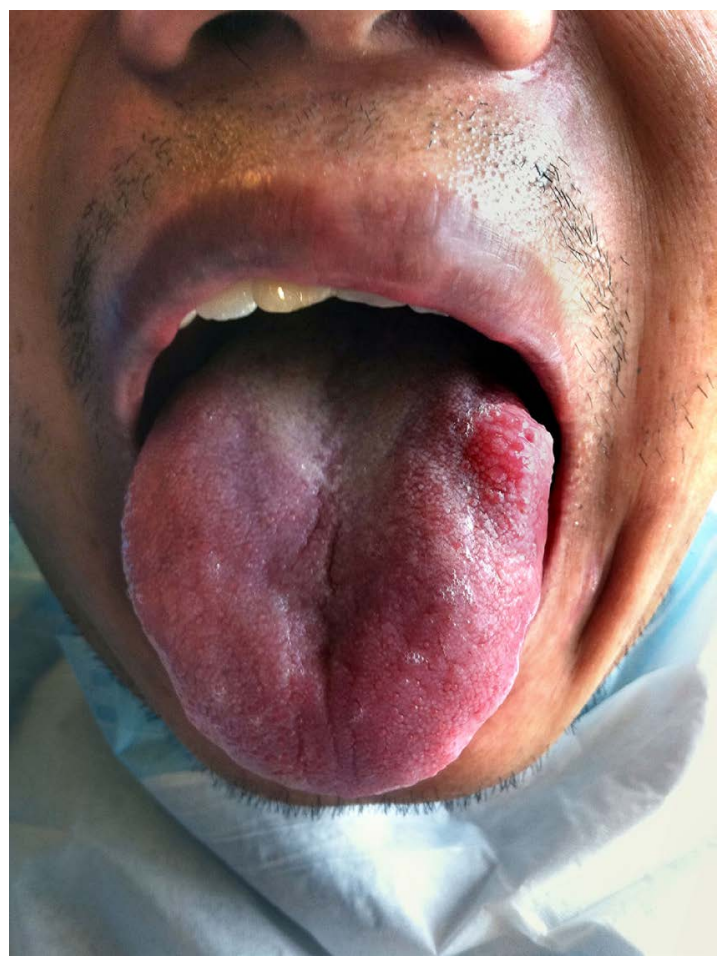

Figure 2. This image shows a $1 \mathrm{~cm}$ firm, round swelling present on the left dorsum of the tongue.

Differential diagnosis of plexiform schwannoma poses a challenge and includes mucocele, granular cell tumour, lipoma, haemangioma, eosinophilic granuloma, epidermoid and dermoid cysts, epithelial hyperplasia, and benign salivary gland tumours. In some cases, glandular malignant processes, squamous cell carcinoma, sarcomas and malignant peripheral nerve sheath tumours may share similar clinical features [16] [17]. Histopathological features of plexiform schwannoma such as frequent cellular morphology associated with hyperchromatic nuclei, increased mitoses, and plexiform growth can suggest a malignant process. It is important to differentiate 
plexiform schwannoma from plexiform neurofibromas and malignant peripheral nerve sheath tumours because plexiform schwannoma follows a benign clinical course, with complete surgical excision being curative [18]. Plexiform schwannoma can have a multinodular or plexiform appearance [19], although the term has been used interchangeably by many researchers [20]. Solitary plexiform schwannoma is characterized by thin capsules, fascicles and multiple interconnecting nodules with presence of Antoni A and focal or absent Antoni B areas [19]. Diffuse and strong positivity with immunohistochemical markers like S-100, laminin and collagen type IV occur in both the types. Radiological investigations of choice include plain film radiography and MRI imaging which allows the assessment of the extent of the lesion, and allows treatment planning for surgical access. However an overlap also exists in the radiological imaging characteristics of schwannoma and other soft-tissue tumours, especially neurofibroma [21]. Treatment of choice of schwannoma in the head and neck region has been surgical removal, with a very low reported rate of morbidity and recurrence [22]. This case report highlights the diagnostic challenges posed by plexiform schwannoma and role of imaging as well as the importance of definitive histopathological analysis and diagnosis.

\section{Acknowledgements and Disclosures}

There is no financial support to be declared and no conflicts of interest. The authors have complied with the ethical guidelines for authorship and publishing.

\section{References}

[1] Skouras, A., Skouras, G., Diab, A., Asimakopoulou, F.A., Dimitriadi, K. and Divritsioti, M. (2011) Schwannoma of the Nasal Tip: Diagnosis and Treatment. Aesthetic Plastic Surgery, 35, 657-661. http://dx.doi.org/10.1007/s00266-011-9656-5

[2] Kohyama, S., Hara, Y., Nishiura, Y., Hara, T., Nakagawa, T. and Ochiai, N. (2011) A Giant Plexiform Schwannoma of the Brachial Plexus: Case Report. Journal of Brachial Plexus and Peripheral Nerve Injury, 6, 9. http://dx.doi.org/10.1186/1749-7221-6-9

[3] Reed, R.J. and Harkin, J.C. (1978)Pacinian Neurofibroma. Histopathology, 2, 153. http://dx.doi.org/10.1111/j.1365-2559.1978.tb01703.x

[4] Suchak, R., Luzar, B., Bacchi, C.E., Maguire, B. and Calonje, E. (2010) Cutaneous Neuroblastoma-Like Schwannoma: A Report of Two Cases, One with a Plexiform Pattern, and a Review of the Literature. Journal of Cutaneous Pathology, 37, 997-1001. http://dx.doi.org/10.1111/j.1600-0560.2009.01455.x

[5] Megahed, M. (1994) Plexiform schwannoma. The American Journal of Dermatopathology, 16, 288-293. http://dx.doi.org/10.1097/00000372-199406000-00011

[6] Wright, B.A. and Jackson, D. (1980) Neural Tumours of the Oral Cavity: A Review of the Spectrum of Benign and Malignant Oral Tumours of the Oral Cavity and Jaws. Oral Surgery, Oral Medicine, Oral Pathology, 49, 509-522. http://dx.doi.org/10.1016/0030-4220(80)90075-4

[7] Woodruff, J.M., Marshall, M.L., Godwin, T.A., Funkhouser, J.W., Thompson, N.J. and Erlandson, R.A. (1983) Plexiform (Multinodular) Schwannoma. A Tumor Simulating the Plexiform Neurofibroma. American Journal of Surgical Pathology, 7, 691-697. http://dx.doi.org/10.1097/00000478-198310000-00009

[8] Enzinger, F.M. and Weiss, S.M. (1995) Soft Tissue Tumors. 3rd Edition, Missouri Mosby, St. Louis, 829-838.

[9] Pfeifle, R., Baur, D.A., Paulino, A. and Helman, J. (2001) Schwannoma of the Tongue: Report of 2 Cases. Journal of Oral and Maxillofacial Surgery, 59, 802-804. http://dx.doi.org/10.1053/joms.2001.24298

[10] Gallo, W.J., Moss, M., Shapiro, D.N. and Gaul, J.V. (1977) Neurilemoma: Review of the Literature and Report of Five Cases. Journal of Oral Surgery, 35, 235-236.

[11] Ferreti Bonan, P.R., Martelli Jr., H., Nogueira Dos Santos, L.A., Comini Mol, V. and Paes De Almeida, O. (2008) Multinodular Neurilemmoma of the Tongue: A Case Report with Differential Immunohistochemical Profile. Minerva Stomatologica, 57, 71-75.

[12] Husain, S., Yunus, M.R., Ramli, R. and Athar, P.P. (2011) Schwannoma of the Tongue in a Ten-Year Old Child. Journal of Pakistan Medical Association, 61, 500-501.

[13] Gallesio, C. and Berrone, S. (1992) Schwannoma Located in the Tongue-A Clinical Case Report. Minerva Stomatologica, 41, 583-590.

[14] Hsu, Y.C., Hwang, C.F., Hsu, R.F., Kuo, F.Y. and Chien, C.Y. (2006) Schwannoma (Neurilemmoma) of the Tongue. Acta Oto-Laryngologica, 126, 861-865. http://dx.doi.org/10.1080/00016480500527219 
[15] Ioannou, M., Papanastassiou, I., Iakowidou, I., Kottakis, S. and Demertzis, N. (2009) Plexiform Schwannoma of the Posterior Tibial Nerve: A Case Report. Cases Journal, 2, 8392. http://dx.doi.org/10.4076/1757-1626-2-8392

[16] Enoz, M., Suoglu, Y. and Ilhan, R. (2006) Lingual Schwannoma. Journal of Cancer Research and Therapeutics, 2, 76-78. http://dx.doi.org/10.4103/0973-1482.25856

[17] Kar, M., Deo, S.V., Shukla, N.K., et al. (2006) Malignant Peripheral Nerve Sheath Tumours (MPNST) Clinicopathological Study and Treatment Outcome of Twenty-Four Cases. World Journal of Surgical Oncology, 4, 55. http://dx.doi.org/10.1186/1477-7819-4-55

[18] Agaram, N.P., Prakash, S. and Antonescu, C.R. (2005) Deep-Seated Plexiform Schwannoma: A Pathologic Study of 16 Cases and Comparative Analysis with the Superficial Variety. The American Journal of Surgical Pathology, 29, 10421048.

[19] Krolls, S.O., McGinnis Jr., J.P. and Quon, D. (1994) Multinodular versus Plexiform Neurilemmoma of the Hard Palate-Report of a Case. Oral Surgery, Oral Medicine, Oral Pathology, 77, 154-157. http://dx.doi.org/10.1016/0030-4220(94)90278-X

[20] Fletcher, C.D. and Davies, S.E. (1986) Benign Plexiform (Multinodular) Schwannoma: A Rare Tumour Unassociated with Neurofibromatosis. Histopathology, 10, 971-780. http://dx.doi.org/10.1111/j.1365-2559.1986.tb02595.x

[21] Beggs, I. (1997) Pictorial Review: Imaging of Peripheral Nerve Tumours. Clinical Radiology, 52, 8-17. http://dx.doi.org/10.1016/S0009-9260(97)80299-1

[22] Cohen, M. and Wang, M.B. (2009) Schwannoma of the Tongue: Two Case Reports and Review of the Literature. European Archives of Oto-Rhino-Laryngology, 266, 1823-1829. http://dx.doi.org/10.1007/s00405-008-0907-2 